\title{
Rules for the effective maintenance of buildings and maintenance of etics system with biocorrosion
}

\author{
Nad’a Antošová \\ Katedra technológie stavieb \\ STU , Stavebná fakulta Bratislava \\ nada.antosova@stuba.sk
}

The External Thermal Insulation Composite System (ETICS) HAS A LONG-TERM PROBLEM WITHOUT A CAUSE THAT HAS YET BEEN DETERMINED - COLONISATION OF THE SURFACE BY MICROORGANISMS. The technical performance and estimated service life of the ETICS system can be ensured through the documentation about its use, maintenance and repairs. The regional legislation does not require the provision of documents about the use of buildings or building parts. The research was therefore focused on suggesting a conceptual manual for the use of the ETICS system and its implementation in practice. The suggested monitoring and management of decontamination technology for the ETICS system allows for an external wall's resistance to microorganisms. The generalised results will be the basis for the creation of a user manual for buildings according to regional standards and legislation. The article relies on research on the destruction of microorganisms on external walls with an ETICS system. 


\section{INTRODUCTION}

The External Thermal Insulation Composite System (ETICS) is an industrially manufactured element built into an external wall directly on a construction site. It contains sticky mortar, thermal insulation material, mechanical anchors, a reinforcing layer and decorative plaster (STN 73 2901). The purpose of the ETICS system is to ensure the thermal and technical performance of a building and to increase its energy performance. However, approximately 3-5 years from its application, microorganisms (algae, cyanobacteria, mould) appear on the external wall, i.e., the biocorrosion of the ETICS system. The consequences of biocorrosion are manifold, including esthetic failures, and in extreme cases, a collapse of the building construction. Biocorrosion is caused by environmental factors together with physical, chemical, building-technical, and technological factors that cannot be separated from each other but must be understood as a specific interactive ecosystem (Johansson, S. et al. 2010). Biological attacks on the surface of an ETICS system is a global problem. It is becoming more unsatisfactory to "return" to a so-called green external wall which is more common in many cases. The cause of biocorrosion is not yet clearly known (Raschle, P. and Büchli R. 2006). For this reason, preventing the biocorrosion of an ETICS system is difficult. Research is focused on assessing the risks of biologically contaminated external walls and on creating maps of high-risk areas (Barreira, E. et al. 2013). But very few experts deal with the maintenance of an existing ETICS system. That is why it is potentially valuable to develop effective rules for its use and maintenance that can be implemented periodically throughout the estimated service life of an ETICS system. It is the only way to achieve the permanent resistance of external walls to microorganisms with the current level of knowledge and findings.
Due to the lack of legislation in Slovakia, this field is lacking a professional approach for the safeguarding and maintenance of ETICS systems, long-term monitoring of their status, documentation of their maintenance, planning strategies and biocorrosion prevention. Instead, we find subjective decisions in managing emergency or operational solutions of biocorrosion in ETICS systems. The demand from the practice is clear and sound: rules need to be determined about the maintenance and use of an ETICS system. Through feedback and monitoring of the status of ETICS systems, opportunities for manufacturers, project managers and designers in the field of prevention are also presented. This is where we can clearly see the possibilities from research with the outcome of a proposed user manual for ETICS systems, with the methods of monitoring biocorrosion and managing decontamination.

\section{Analysis - Legislative support} of the documentation for the use of buildings in Slovakia

Every product, new or used, movable or immovable, which is part of another movable or immovable thing and which is intended to be used by consumers must include information about its characteristics and methods for its use and maintenance. If it is necessary because of the type of product and its methods and duration of use, the seller must ensure that this information is clearly contained in the written instructions provided. These requirements are set by the Act on the Protection of Consumers (Act of the National Council of the Slovak Republic No. 250/2007).

As a set of rules on the use and maintenance of buildings and their components, building manuals are mentioned in the Slovak legislation rarely and only marginally. According to (Appendix 5 of the Act of the National Council of the Slovak Republic No. 25/2006), the basic requirements for construction regarding the characteristics of a product and the conditions for its use (i.e., a user manual) published by a relevant person must be complied with.

On the other hand, according to (Public notice of the Ministry of the Environment 532/2002), a construction authority can order documentation about the actual effectuation of a building to be made, in the event this has not previously been made or preserved. This is a simple document, a so-called building passport, which according to (Public notice of the Ministry of the Environment 532/2002), includes details about the type and purpose of the building with a description of the use of its rooms. However, a requirement for documentation about the method of use, the maintenance and safeguarding of buildings, and their fittings and equipment is lacking.

The holes in the field of user manuals and legislation in Slovakia are partially filled in by (Act of the National Council of the Slovak Republic No. 254/1998), which requires this documentation in the case of public construction works. According to (Act of the National Council of the Slovak Republic No. 254/1998 ), documentation about the quality of public works must include a plan for the use of public works, i.e., a user manual.

To summarise, as can be seen from the analysis of the legislative support above, there is no obligation to create a manual for using a building, or for its maintenance and repair. This presents an opportunity for research, and its implementation in practice and the generalisation of its results could be the basis for such new legislation.

\section{ETICS user manual}

The life cycle of a building (or a building construction such as an ETICS system) has three basic periods: preparation, implementation and use (see Picture 1, below). There are two important milestones in the cycle representing a change in intention: the idea for execut- 
ing the building and the change from executing the building to putting the building into use. The beginning of the application of an ETICS system is accompanied by extensive documentation required by legislation. At the beginning of its use, the documentation about rules and methods for using an ETICS system is underestimated or even lacking.

When we consider that the average time for the preparation and realisation of $\mathrm{n}$ ETICS system is 2-4 years and that the average estimated time of use is 15-20 years, the underestimation of providing rules on the use and maintenance of an ETICS system is clearly not right.

tampering with the ETICS system and the consequences of this tampering on the warranties and durability of the ETICS system. It is also said in these standards that achieving the estimated service life of an ETICS system is conditional on the use and maintenance according to the documentation of the ETICS system. The conditions for the use and maintenance are provided by the manufacturer, as per the appendices of the technical standards.

The requirement to make a user manual is therefore put on the manufacturers of ETICS systems, as per regional legislation (Appendix 5 of the Act of the National Council of the Slovak Republic No. 25/2006). The design of

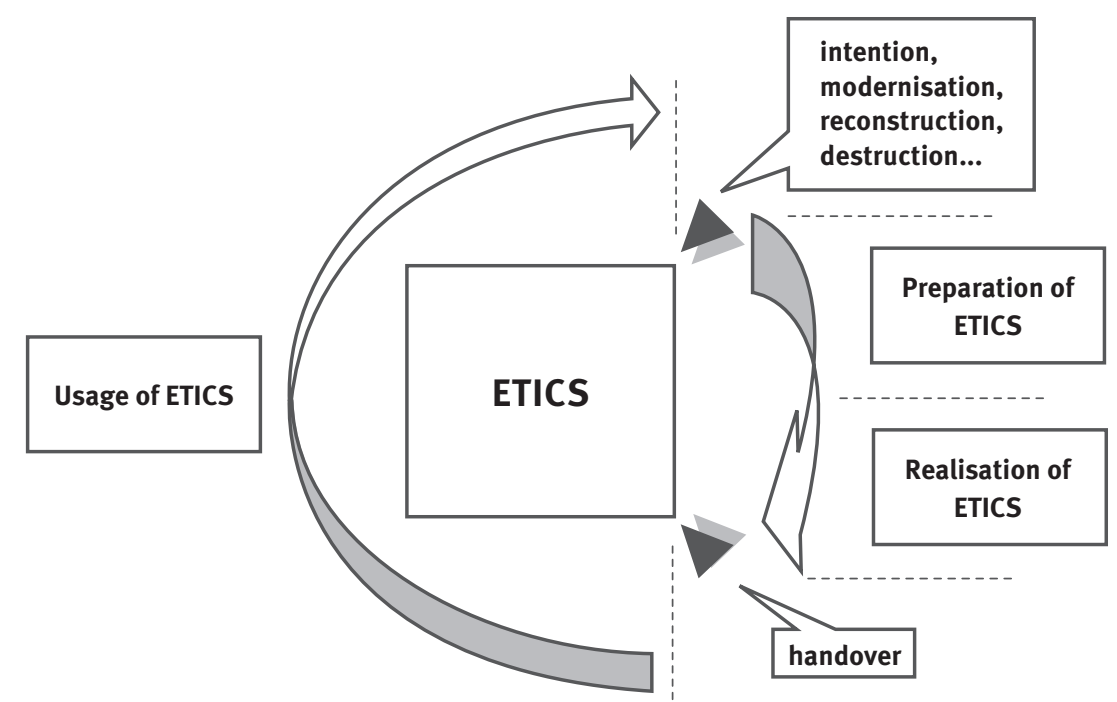

Picture 1 Life cycle of an ETICS system. This picture shows the difference in time between the period of the preparation and execution of an ETICS system and the period of the use of the construction. Technical documentation is only required by regional legislation in the period of the preparation and execution of an ETICS system, but no documentation exists for the use of an ETICS system (Antošová N. 2012).

The terms for the use and maintenance of an ETICS system are set by the relevant technical standards (STN 73 2901) on the implementation of outside thermal insulation contact systems. These terms are limited to the users and operators of an ETICS system, who must learn about the disadvantages of an ETICS system, especially the specific details, is coordinated by the manufacturer together with the project manager. The builder of an ETICS system builds the construction into the building. Such a person is required to have a professional qualification to do this activity (STN 73 2901). The owner, user, caretaker or facility manager oversees the maintenance of the ETICS system. A list of suggested tasks for cooperation and responsibility in creating a user manual for an ETICS system by each of the persons involved is presented in Table 1 below.

The user manual must be understood as part of the documentation of the whole system of controlling the quality. In general, it should consist of four basic parts:

Description of the actual status of the ETICS system - monitoring

Rules for using the ETICS system

Rules for checks - inspections

- Rules for maintenance and repairs database of operational and planned interventions

The end result of the user manual must be a complex document - a guidebook for its users. It is clear from the required breadth and content of the manual, that it must be devised by the manufacturer, project manager, designer and caretaker of the ETICS system. The basic information is provided by the manufacturer, and then the project manager and designer must add rules for its use based on the actual status of the system. The caretaker will use the information and rules during the necessary interventions and repairs, and will update the information. With such feedback, the development of the components, status of its construction and the prolongation of its durability will be improved.

Description of the actual status of an ETICS system - monitoring

A description of the actual execution of the construction of an ETICS system will be part of the user manual. It will contain information about the project manager, the designer and his subcontractors, information about the length of the warranty of the system and its components, data on any complaints or unfinished tasks, and also the conditions for the validity of the warranty. The documentation should also con- 


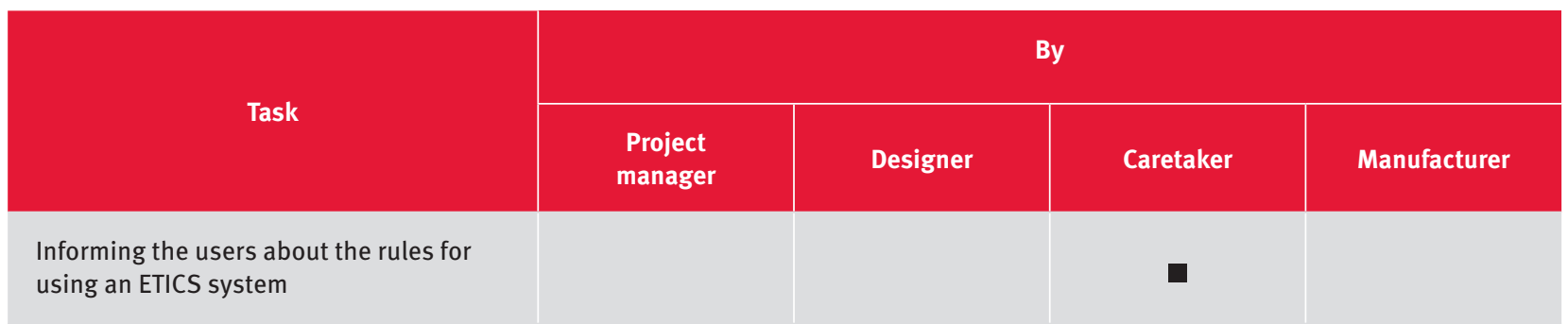

Determining the person responsible for using an ETICS system in accordance with the manual

$\begin{aligned} & \text { Summary of the materials and compo- } \\ & \text { nents of an ETICS system }\end{aligned}$
$\begin{aligned} & \text { Rules on using components of an ETICS } \\ & \text { system }\end{aligned}$
$\begin{aligned} & \text { Rules on technical checks of an ETICS } \\ & \text { system }\end{aligned}$

Visual inspections of ETICS system

Technological methods of maintenance interventions and repairs

Determining the corridors of access for maintenance interventions and repairs

Determining the site for construction equipment during the intervention

Plan of maintenance and repairs during the lifetime of an ETICS system

Updating maintenance and repairs plans

Guidebook for users of an ETICS system

Table 1 Cooperation and responsibility of persons when making an ETICS user manual. The suggested tasks and responsibilities can be modified according to and based upon (Fickuliak I. 2003) for the construction of an ETICS system. This would be part of the first chapter in the ETICS user manual / Legend: $\square-$ responsible, $\square-$ cooperates

tain important information about the possible maintenance and repairs of the ETICS system. This means providing at least the contact information of the suppliers of the components who are allowed, qualified and acceptable to intervene into the ETICS system during the warranty period and even afterwards.

All these records are sources of information to be used in repairs, reconstruction, building adjustments, interventions into the ETICS system or planned maintenance. It is expected that during the use of the ETICS system, these records will be chronologically updated. Together with the description of the actual implementation of the ETICS system, these records will create a standard for a comparison of the status at any time during the use with the status when the work was finished.

\section{Rules on using an ETICS system}

The rules on using any product or building are devised in such a way that no person or property is endangered, harmed or damaged.

In the case of an ETICS system, the user or caretaker must be made aware of the consequences of his subjective interventions into the ETICS system when the work is finished. This mainly concerns any punctures, anchoring or 


\begin{tabular}{|c|c|c|c|c|}
\hline \multicolumn{4}{|c|}{ Protocol from checks of ETICS } & Protocol number: \\
\hline \multicolumn{5}{|c|}{ Identification of the object } \\
\hline 1 & Town: & & & \\
\hline 2 & Street, number: & & Reg. no.: & Number of flats: \\
\hline 3 & $\begin{array}{l}\text { Outer wall orientation in } \\
\text { relation to cardinals: }\end{array}$ & & & \\
\hline 4 & Realisation of ETICS in: & Age: & Number of floors: & \\
\hline
\end{tabular}

\begin{tabular}{|c|c|c|c|c|c|c|c|c|c|}
\hline \multicolumn{10}{|c|}{ Information about the composite insulation system } \\
\hline \multirow{2}{*}{5} & \multirow[t]{2}{*}{ Layer composition of ETIC: } & \multicolumn{5}{|c|}{ Insulation: } & \multicolumn{3}{|c|}{ Surface adjustment (plasters): } \\
\hline & & $\begin{array}{l}\text { mineral } \\
\text { fibres: }\end{array}$ & polystyrene: & combination: & other: & dispersed: & silicon: & silicate: & mineral: \\
\hline 6 & $\begin{array}{l}\text { Appliances of the outer- } \\
\text { wall (passages, grates, } \\
\text { hinges,technology...): }\end{array}$ & & & & & & & & \\
\hline
\end{tabular}

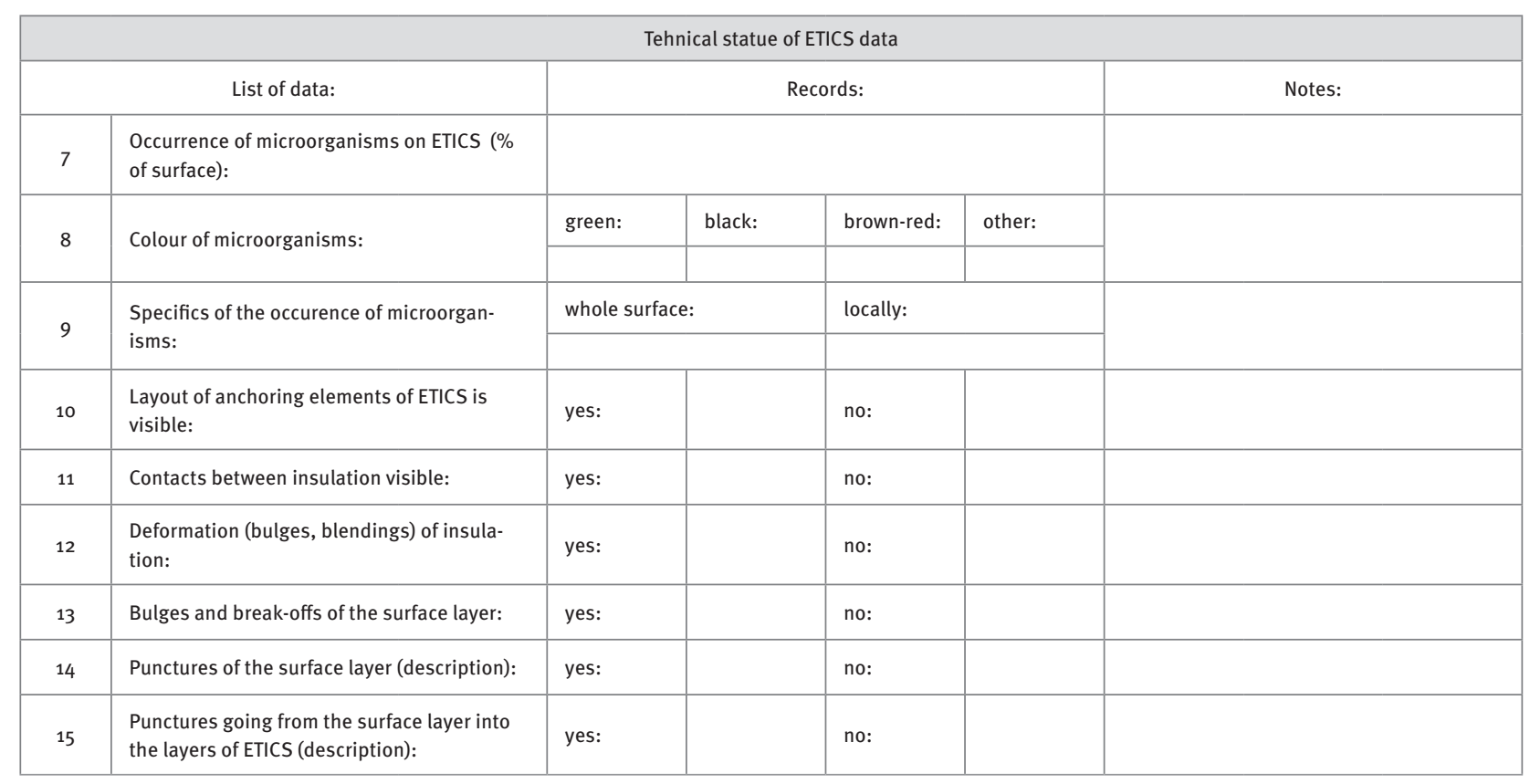

\begin{tabular}{|c|l|l|l|l|l|l|}
\hline \multicolumn{2}{|c|}{ List of data: } & \multicolumn{3}{c|}{ Diagnosis } & \multicolumn{2}{c|}{ Records: } \\
\hline 16 & Taking of microbiological material: & yes: & & no: & \\
\hline 17 & Thermal diagnosis: & yes: & & no: & & \\
\hline 18 & Measurement of puncures (description): & yes: & & no: & & \\
\hline
\end{tabular}

\begin{tabular}{|l|l|l|l|l|l|}
\hline & Participated: & user /caretaker & & creator & \\
\hline & Signature: & & & \\
\hline & Noted by: & On: & & & \\
\hline & In: & & & \\
\hline
\end{tabular}

Table 2 Protocol for technical status check of ETICS. List of basic control tasks, used in the prevention of the biocorrosion of the components. This would be a part of the third chapter in the user manual for an ETICS system (Antošová, N. 2007). 
installation of any satellite receivers, clothes driers, air-conditioning units, railing, roofs, additional glass, etc. The consequences of these interventions have a large impact on the warranties provided and on the durability of an ETICS system.

The user or caretaker of an ETICS system must be made aware of the necessity of carrying out periodical repairs of the surfaces, so that any defects can be avoided as much as possible. Due to the occurrence of biocorrosion, the rules must also contain important information about the necessity of carrying out periodic maintenance by cleaning the surface of the ETICS system and renewing its biocide protection.

The basic instructions and rules must be accessible to all who come into contact with the ETICS system in relevant cases (user, caretaker, maintenance, repairmen, etc.).

Rules on checks - inspections

Rules on inspections of an ETICS system are tied to the most common defects and failures of ETICS system recorded in research and development studies and in their manufacture and execution in the past.

In Table 2, you can see an example of a protocol for a technical status check of an ETICS system. The protocol is intended to discover symptoms of biological coating. The form is sufficient for monitoring the risk of biocorrosion or monitoring the durability and effectiveness of any previous decontamination. The conclusions reached from using the protocol serves as a tool in the decisionmaking process regarding further maintenance or repairs.

List of basic control tasks, used in the prevention of the biocorrosion of the components. This would be a part of the third chapter in the user manual for an ETICS system (Antošová, N. 2007).

In relation to the occurrence of biocorrosion on the surface or the structure of an ETICS system, the periodicity of inspections is connected to the long-term monitoring of the re-occurrence of microorganisms (cyanophytes, frustules, green algae, micromycetes) on the surface of the outer wall. The periodicity is closely connected to the factors that impact or eliminate the development of the microorganisms. This article, due to limited space, is not concerned with a detailed analysis of the causes of and conditions for such development. The information and conclusions from the research and monitoring were published separately (Antošová, N. 2011) and (Antošová, N. 2007). The periodicity of inspections in relation to the occurrence of biocorrosion is also connected to the durability of the intervention - decontamination by biocide, or algaecide products. The lifespan of chemical products on an exterior is short (around 2-5 years). The first easily visible coating of microorganisms can be noticed after about 2-3 years from the estimated lifespan of an intervention.

The purpose of systematic planned inspections of an ETICS system is in the first place, the early discovery of defects and damage and preventing them from spreading. Neglect could lead to increases in the cost of repairs and, in extreme cases, to shortening the durability or causing the collapse of the system. A secondary, but not less important purpose, of the checks, is gathering the results from the inspection. These are an important source in deciding which intervention from the maintenance, decontamination, repair or reconstruction databases to choose.

A professional ETICS inspection consists of basic control tasks that include information about the site in the ETICS system where it should be done, who can do it, and what collection of information is necessary to assess the technical status. The method of any potential laboratory diagnosis should also be determined. An ETICS user manual must contain the method of making notes from the inspection and the method of assessing the results obtained. The notes must be chronologically archived throughout the whole period of the use, so as to create an actual confrontational etalon at any time during the use.

Rules on maintenance and repairs database of operational and planned technological steps concerning maintenance and repairs

The rules for the use of an ETICS system and the proposed technological processes to execute interventions for maintenance and repairs according to Table 1 require active cooperation with the manufacturer of the ETICS system. In practice, however, the instructions by the manufacturers are general, and limited to information about the "nonmaintenance" of the ETICS system, or about the necessity for the basic cleaning of the surfaces as is necessary. Only rarely is there information on the technological processes to execute interventions for maintenance and repairs so as to resolve mechanical damage, punctures or the cleaning method and using a cleaning product (http://www. extherm.com), (http://www.weber-terranova.sk/kontaktne-zateplovacie-systemy-ETICS system.html).

In an ETICS user manual, the rules should be expected to contain not only the technological processes of any interventions for maintenance and repairs, but also basic information about the necessary preparatory and ancillary work, work and protective aids, accesses and corridors of the intervention and places necessary for the equipment on the building site. The compilation of the maintenance rules must contain a basic database of the technological processes to execute any interventions, which (together with the information from monitoring and inspecting the ETICS system) will enable the caretaker or user to make decisions easily. The database of interventions must cover the basic methods for the maintenance of the ETICS system - the preventative, operational 


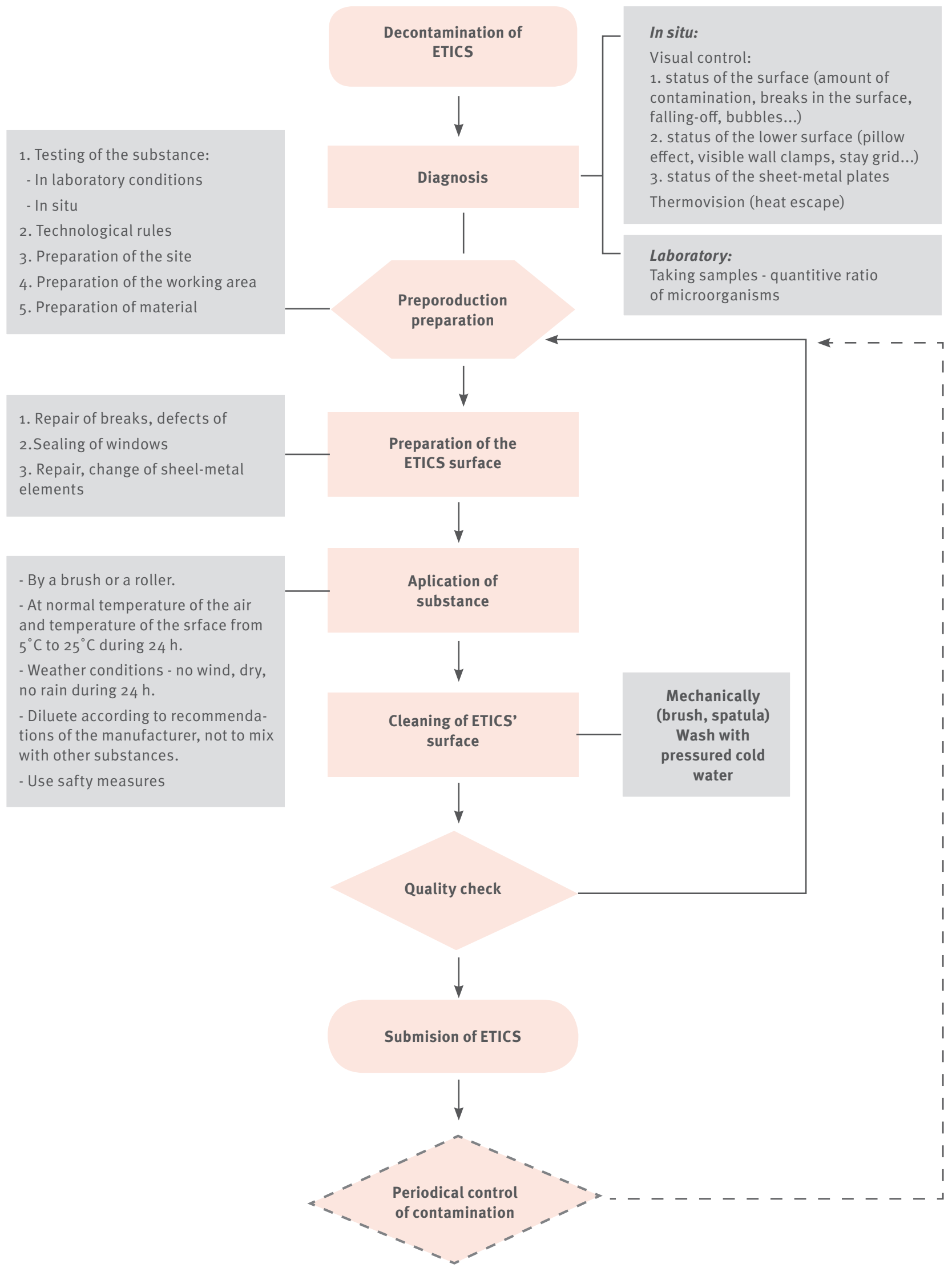

Picture 2 Flow chart: operative leadership of a decontaminative intervention into an ETICS system. This would be part of the fourth chapter in the ETICS user manual - a database or repairs (Antošová, N. 2011). 
and emergency methods. It is necessary to mention that in the case of the occurrence of microbiological material on the surface of the outer wall, one must always decide between an intervention that is:

$\checkmark$ conservative (direct or indirect), or $>$ radical,

which is almost always connected with other defects, the functionality, or the age and durability of the ETICS system.

The periodicity of the maintenance of an ETICS system is a much debated topic. The periodicity of the maintenance of a composite thermal insulation system is determined by the durability of the limiting element in the system or the durability of the protection of that element (e.g. waterproofing, protection by biocide appliances). The durability of plaster is said to be between 20-60 years and the cycle for maintenance is recommended to be 10-25 years (Sternová Z. et al. 2001). The durability of an ETICS system is approximated at 80-100 years and the cycle for maintenance is suggested to be 40-55 years (Sternová Z. et al. 2001). The final layer consists of a thin plaster, and the protective biocide appliance has a lifetime of 2-5 years (Antošová, N. 2011) and (Antošová, N. 2007).

Picture 2 above shows an operative or preventative intervention for the destruction of the microbiological coating on the surface of an ETICS system. Several external walls in Slovakia were cleaned and further monitored between 2002 and 2012 as per this diagram. The results are satisfactory. The durability of the biocide appliances applied reached a maximum of five years on the exterior, but the monitoring and repeated maintenance achieved a long-term resistance of the surface of the ETICS system against algae, cyanobacteria and mould. This diagram has been implemented and verified in practice and can be used as part of the database of the repairs and maintenance of an ETICS system.
It can be concluded from the research and empirical conclusions, that the cycle for maintenance (prevention and protection) of the final layer of an ETICS system is directly connected to the efficiency and lifespan of the chemical product used during any decontamination or prevention. The durability of interventions is limited by legislative conditions. It is possible to use a biocide product capable of the destruction or decontamination of harmful organisms, but it must be a product that presents a small risk of an adverse impact on people, animals and the environment and that contains no important effective substances. The products must be dissolved in water without the possibility of any damage to the environment (Public notice of the Ministry of the Environment 532/2002).

The proposed cycle of the maintenance and protection of an ETICS system in relation to its resistance to biocorrosion is in an interval of 3-6 years (Antošová, N. 2007). The maintenance and improvement of the resistance of an ETICS surface to microorganisms cannot be conducted without the necessary technological interventions for the maintenance and repairs of punctures, damage, defects and related elements.

The cycle of maintenance of an ETICS system results from specific conclusions gained from monitoring and inspections and depends on the overall characteristics and technical status of an ETICS system.

Records concerning all the completed interventions must be kept in the user manual and can be used for statistical assessments of their frequency, costs, difficulty and work of professionals, etc. The records are useful for assessing the efficiency of maintenance, especially in the period nearing the end of its estimated service life. The life cycle of an ETICS system is closed; the user, caretaker or owner is at a crossroads - a decision between modernising, rebuilding or destroying of the ETICS system construction must be made.

\section{Discussion}

A chronically repetitive failure of a construction is a breach of the duty of the seller to inform the consumer about the method for the use and maintenance of the product or service provided. Problems occur not only with the setting of requirements and rules on the use and maintenance of a building and its fixtures, but also with the possibilities of asking for a refund. The method of dealing with complaints is almost always handled by a complex technical assessment of the status of the construction or material by an officially appointed expert or an authorised person (Act of the National Council of the Slovak Republic No. 250/2007). The result of the assessment is an expected determination of conformity, i.e., a determination as to whether the actual characteristics of the product correspond with the technical requirements set for that product, under the assumption of proper use and maintenance, but the rules of proper use and maintenance are usually not available.

\section{CONCLUSION}

The life cycle of a building or construction includes the phases of obtaining, executing, using and destroying the building. All the phases of the life cycle of a building result in expenses. The expenses of an ETICS system in the use phase can be significantly lower if effective forms of maintenance through clear rules in a user manual are performed. However, there is no obligation in Slovakia to create a manual for using a building, or performing its maintenance or repair. The maintenance is often unplanned, unsystematic and cost-inefficient. The research presented in the article confirmed the thesis that through periodic monitoring and maintenance of an ETICS system, its surface resistance to microorganisms can be ensured for long periods of time. It was shown that the estimated service life of an ETICS system can be achieved through controlled mainte- 
nance with the help of a user manual. The generalisation of these results will form the basis for the initiation of a user manual in technical standards and regional legislation. The results from monitoring can be used in further research into the causes of the colonisation of external walls by microorganisms, in the development of databases of technical solutions, and adapting the characteristics of an ETICS system to decrease the risks of biocorrosion.

\section{Acknowledgment:}

This contribution is supported by VEGA No. 1/0184/12. Automatic modelling system of mechnical building processes with the application of methods of multicriterial optimalisation. Head of solving group: Prof. Ing. Jozef Gašparík, PhD., Slovak University of Technology in Bratislava, Faculty of Civil Engineering, Department of Building Technology.

\section{References:}

Antošová N. (2012) “Methodological approach to the manual use of ETICS in terms of legal and technical aspects" (Metodologický prístup k tvorbe manuálu užívania ETICS z hl'adiska právnych a technických aspektov), Podlahy a povrchové úpravy ve stavebníctví 2012: Sborník příspevků $z$ konference. Prague: Betonconsult, s.r.o., Prague, pp. 185-191.

Antošová, N. (2007) Biocorrosion of composite insulation systems. Analysis of causes and technology of decontamination. (Biokorózia kontaktných zateplovacích systémov. Analýza príčin a technológia dekontaminácie,), Monograph, Bratislava.

Antošová, N. (2011) Selected technology for the protection and maintenance of additional insulation composite systems (Vybrané technológie ochrany a údržby kontaktných zateplovacích systémov), Tribun EU, Bratislava.

Appendix 5 of the Act of the National Council of the Slovak Republic No. 25/2006 Z.z. on public acquisition.

Barreira, E. et al. (2013) Biological Defacement of External Thermal Insulation Composite Systems. Building Pathology and Rehabilitation., Springer-Verlag Berlin Heidelberg 1, Berlin (eBook).

Fickuliak I. (2003) "Manuals of buildings", Manuály stavieb, Stavebnícka ročenka 2004, Manažment v stavebníctve, Jaga Group, v.o.s. Bratislava, Bratislava, pp. 210-213.

Installation instructions for external composite thermal insulation system (ETICS) EXTHERM, available at http://www. extherm.com (accessed 10.01.2013).

Johansson, S., Wadsö, L., Sandin, K. (2010) "Estimation of mould growth levels on rendered façades based on surface $\mathrm{RH}$ and surface temperature measurements". Building and Environment, p.45.

Public notice of the Ministry of the Environment $532 / 2002$ that sets out the details about the general technical requirements for construction and about the general technical requirements for buildings used by disabled persons.

Raschle, P. Büchli R. (2006) Algen und Pilze an Fassaden Ursachen und Vermeidung 2./2006, Fraunhofer IRB Verlag, Stuttgart.
Sternová Z. Et al. (2001) Renovation of residential buildings (Obnova bytových domov), Jaga group, Bratislava.

STN 73 2901, Execution of external thermal insulation composite systems (ETICS SYSTEM).

Technological decree weber.therm plus ultra, available at http://www.weber-terranova. sk/kontaktne-zateplovacie-systemy-ETICS system.html (accessed 10.01.2013).

The Act of the National Council of the Slovak Republic No. 250/2007 Z.z. on the protection of consumers, as amended.

The Act of the National Council of the Slovak Republic No. 254/1998 Z.z on public works, as amended. 